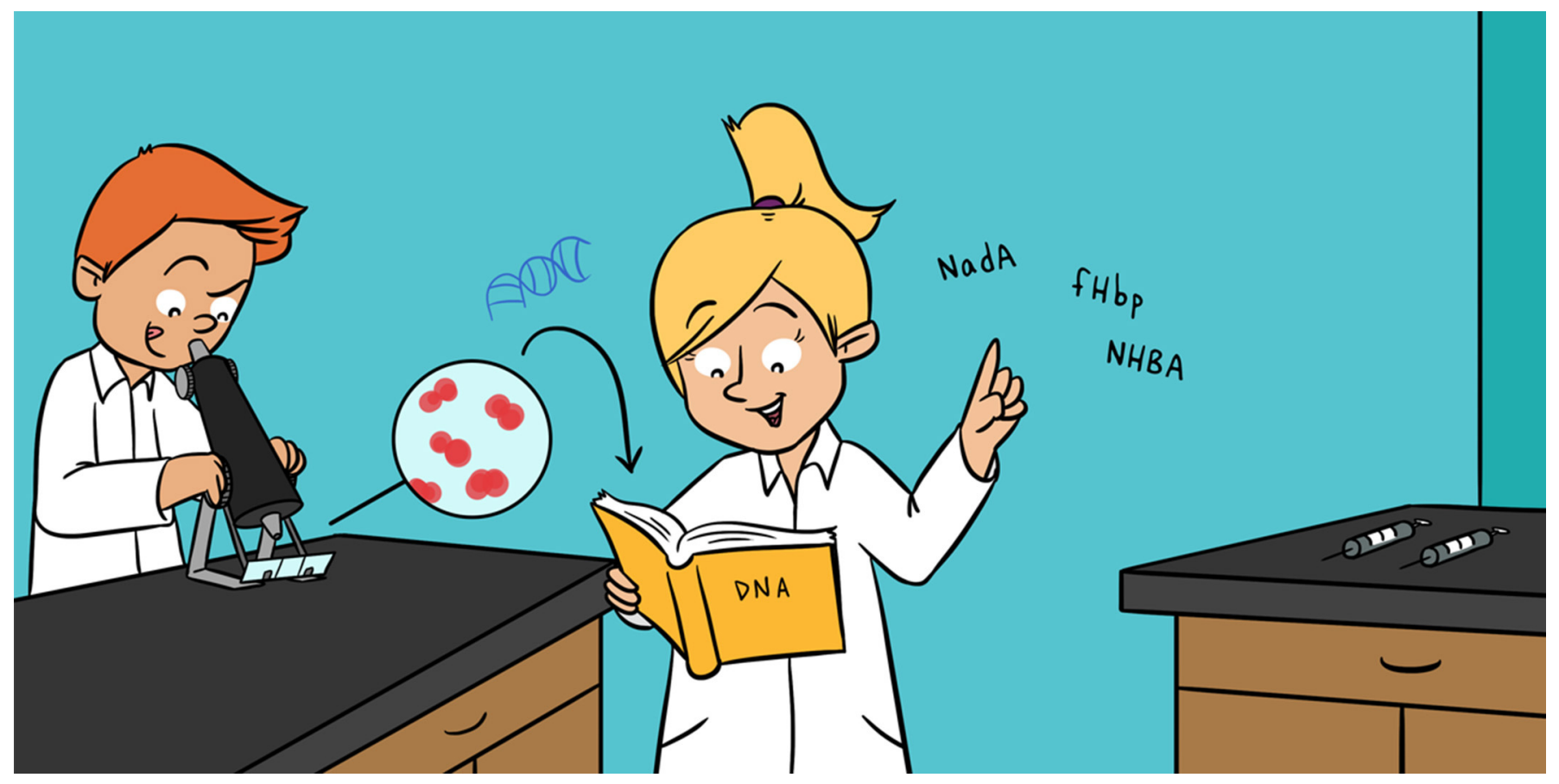

\title{
MENINGOCOCCAL VACCINES: A TECHNOLOGICAL REVOLUTION
}

\section{Simone Pecetta, Vega Masignani, Mariagrazia Pizza and Rino Rappuoli *}

Research and Development Centre, GlaxoSmithKline (GSK), Siena, Italy

\section{YOUNG REVIEWERS:}

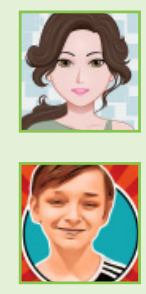

AMELIE

AGE: 12

AGE: 10
ELLIOT
The sneaky meningococcus is a bacterium that can cause terrible disease. Development of an effective vaccine has been extremely difficult. Meningococcal vaccines developed in the 1990s are based on the bacterial capsule, a shield that protects the bacteria and that is used to instruct our body to combat this terrible disease. These vaccines work against four types of meningococcus: A, C, $W$, and $Y$. However, they do not work against meningococcus $B$. Scientists had to invent a completely new way to make vaccines, reading the bacterial DNA to search for new protective components. With this new approach, named reverse vaccinology, three new bacterial components were discovered: NadA, NHBA, and fHbp. When combined with a fourth component (PorA), they form the $4 C M e n B$ vaccine. This vaccine has reduced meningococcal disease in infants by $75 \%$ in the UK. Today, 4 CMenB protects children all around the world. 
Figure 1

How meningococcus invades the body. Meningococcus enters the nose, contacts the cells inside the nostrils, and moves into the blood. There, covered by its capsule and disguised by coating itself with human proteins, (like $\mathrm{fH}$ ) it evades the body's defenses and starts dividing. When meningococcus reaches the organs and the brain, it causes great damage.

\section{VACCINE}

A purified component injected to train the body to remember an infectious organism, so that when we get infected for real, we do not get sick.

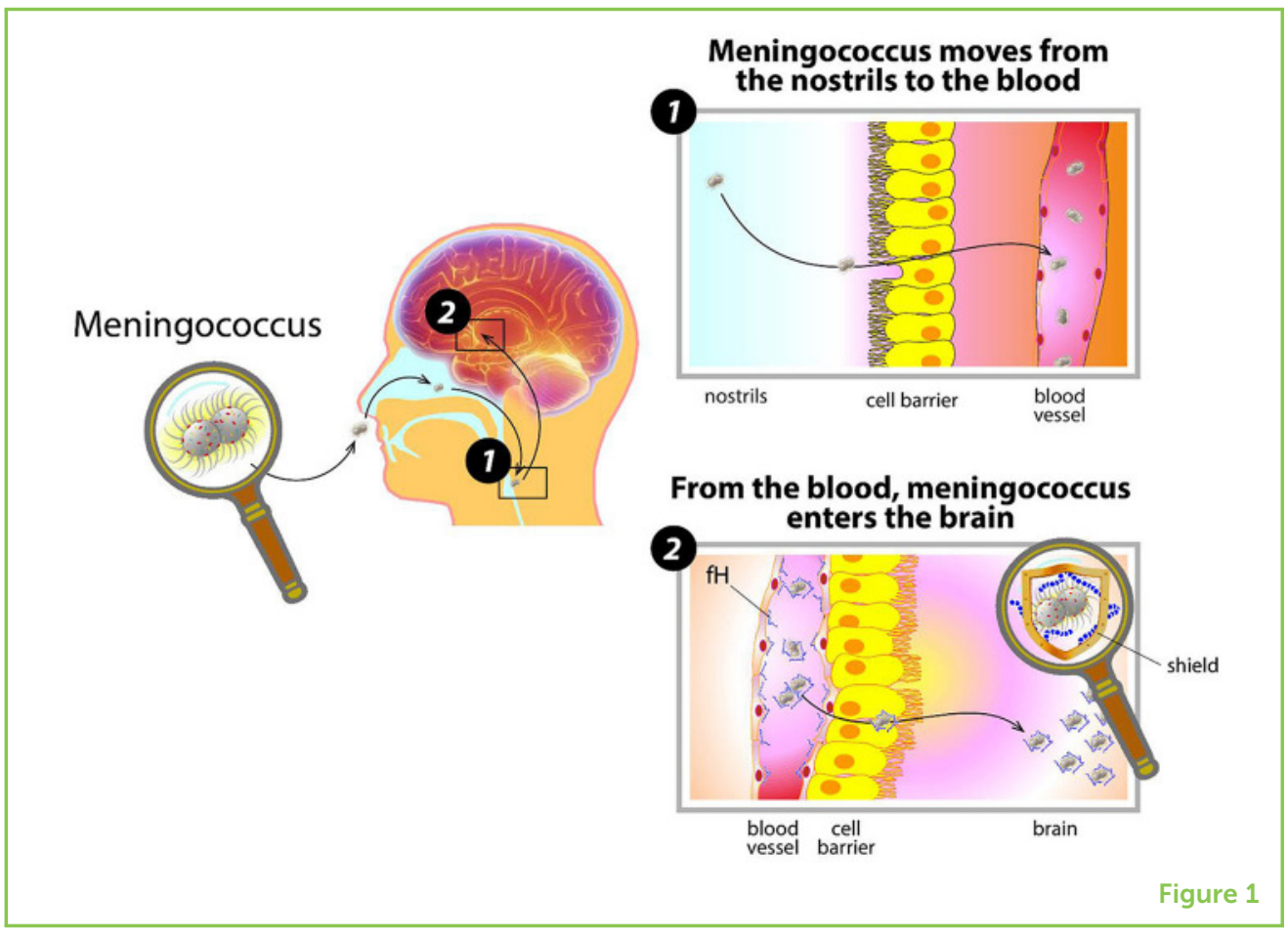

\section{MUCH WORSE THAN A HEADACHE}

You may not have heard of it, but there is dangerous microscopic organism called Neisseria meningitidis, also known as meningococcus. It is a bacterium, made of one single cell. Usually, meningococcus lives quietly in our noses or throats for some months. Sometimes, when we are sick or weak, it can move from the nose to the blood and cause sickness.

Meningococcus is the cause of a severe disease called meningitis that can initially cause fever, vomiting, and headache, like a simple flu. Then, the bacteria begin to travel through the body and grow very quickly, reaching the blood, nerves, and brain (Figure 1). Meningococcal meningitis can cause death in few hours. For those who survive, it can unfortunately lead to physical and mental disabilities, amputation of arms, legs, fingers, and toes. Infants and children are particularly vulnerable to meningococcal disease, and disabilities can occur in up to half of the cases. So why have not you heard of such a scary bacterium before? Because it is not very common. The disease is most present in Africa, south of the Sahara Desert, where 30,000 people get sick every year. But meningococcus sometimes spreads all over the world, often appearing in small outbreaks (it is common in gatherings of young adults in colleges and discos, for example) or in big epidemics. So, how do we avoid getting this bad disease? Well, with vaccines! 


\section{ANTIGEN}

A component of an organism that can cause protection. A vaccine uses one or more antigens to teach the body how to defend against disease.

\section{CAPSULE}

A shield that surrounds a bacterium and protects it from the environment and our immune cells.

\section{ANTIBODY}

Molecules that bind to foreign components like bacterial capsules or antigens. The body's defenses recognize the antibody "tag" and act to stop infection.

\section{CARRIER PROTEIN}

A molecule obtained from bacteria which is highly attractive for $\mathrm{T}$ cells. It is used in conjugate vaccines.

\section{CONJUGATE VACCINE}

A vaccine composed of the bacterial capsule attached to a carrier protein. It can activate both $\mathrm{B}$ and $\mathrm{T}$ cells, and to protect children from meningococcus type $A, C, W$, and $Y$.

\section{FINDING THE WEAK SPOT}

What does meningococcus look like? Like all other cells, it is surrounded by a membrane on which many structures, called antigens, are located. These antigens help the bacterium to attach to our noses and survive in our bodies. Covering the membrane, meningococci have a shield, called the capsule, which protects them from the environment, and most importantly, from the body's defenses. It takes the human body some time to prepare to fight meningococcus, and when the body is ready to destroy the bacteria, it is already too late: meningococcus multiplies rapidly in the blood, enters the organs and the brain, and causes great damage.

The capsule, the main defense mechanism of this bacterium, can also be our best weapon against it. Scientists have discovered that we can inject part of this capsule into a healthy person to teach the body how to defeat meningococcus. It is like showing the identification of a thief to the police, so that they can stop him before he steals. This teaching lesson is called vaccination.

Cells called B cells are part of the police force of our bodies, required to protect us from meningococcus. B cells produce molecules called antibodies. Antibodies are released into the blood and stick to the nasty bacteria, like a tag. After being tagged, the body can destroy the bacteria before they cause any damage.

\section{HISTORY OF MENINGOCOCCAL VACCINES}

The first meningococcal vaccines made of the bacterial capsule only protected adults, and only for a short period of time. In children, the population most vulnerable to meningococcal disease, these vaccines were not useful. The reason is that the capsule alone can only recruit B cells, but it does not call into action other defense cells, called T cells, which are extremely important to protect children. $T$ cells do not produce antibodies but instruct the B cells on how to make better, more precise antibodies and for longer periods of time-kind of like coaches. Thanks to our $\mathrm{T}$ cells, our bodies can remember an infection for years and be ready to fight more rapidly if the same infection-causing organism comes back. So how do we protect children if the capsule is not enough?

Scientists solved this problem in the 1990s: using chemistry, they linked the capsule to another molecule that is highly attractive for $T$ cells [1]. This molecule comes from other nasty bacteria, such as diphtheria or tetanus, and it is called a carrier protein because it delivers the capsule to the $T$ cells. In this way, the vaccine can stimulate both B and T cells. This brilliant idea led to the creation of what are called conjugate vaccines, which are commonly used worldwide today. 
However, meningococcus is a master of disguise: the capsule can be of different types: A, B, C, W, and Y. If the body creates antibodies specific for one type, they are not protective against the others. To be protected against all types, we should teach our bodies to recognize all five variants of the capsule. Conjugate vaccines are highly protective against types A, C, W, and Y. But what about type B? Well, meningococcus had one more trick up its sleeve...

\section{MENINGOCOCCUS B: THE LAST FRONTIER}

The development of a vaccine against meningococcus B represents one of the milestones of modern medicine $[2,3]$. Meningococcus $B$ is a major cause of disease in the Americas, Canada, Europe, Asia, and many other countries. The stumbling block was that the B capsule does not cause antibodies to be produced, not even with the conjugation technology. The sneaky meningococcus $B$ uses a sophisticated strategy: its capsule mimics the sugars presents on our cells, so that it can go under-cover as a harmless human cell. As a result, by attacking the meningococcus $B$ capsule, the body could also damage its own cells, and that is why the immune system does not react to it. Many scientists concluded that using the capsule to fight meningococcus $B$ could be too risky. A new technology was needed to overcome this challenge.

\section{AN INSIDE-OUT REVOLUTION}

If a problem cannot be solved using well-known methods, you must invent something new! Instead of looking for something clearly visible outside the bacterium, like its capsule, scientists decided to study the bacterium more deeply, looking at its DNA. The DNA is like a catalog of all the bacterial components that perform the functions of the bacterium. Using modern lab equipment, the DNA can be read like a text, exactly as you are doing with this manuscript (more than 2 billion letters and more than 2,000 words are contained in the meningococcal DNA!). While reading, you may recognize words that you do not know, and search for their meaning using a dictionary. Well, this is exactly what happened for meningococcus B. Scientists read its DNA to find yet-unknown bacterial components that, like the capsule in the other types, could be good targets for the body's defenses. This

REVERSE VACCINOLOGY

The study of the DNA of an organism to identify new components for vaccines. approach, from outside to inside, was called reverse vaccinology, and represented a revolution in the world of vaccines (Figure 2).

Sophisticated computer algorithms were used to screen the entire DNA of type B meningococcus and several months of work were necessary to go from 2,000, down to 600 potential antigens, and finally to the three best ones [4]. The top three components were called NadA, fHbp, and NHBA. 
Figure 2

Reverse vaccinology. DNA from

meningococcus is read by a machine called a sequencer. With the use of sophisticated computer programs, the DNA is analyzed to identify new components to be used for a vaccine. After many experiments, three antigens were identified with the potential of protecting against

meningococcus $B$ : $\mathrm{NadA}, \mathrm{NHBA}$, and fHbp. Combined with a fourth antigen, PorA, they form the 4CMenB vaccine.

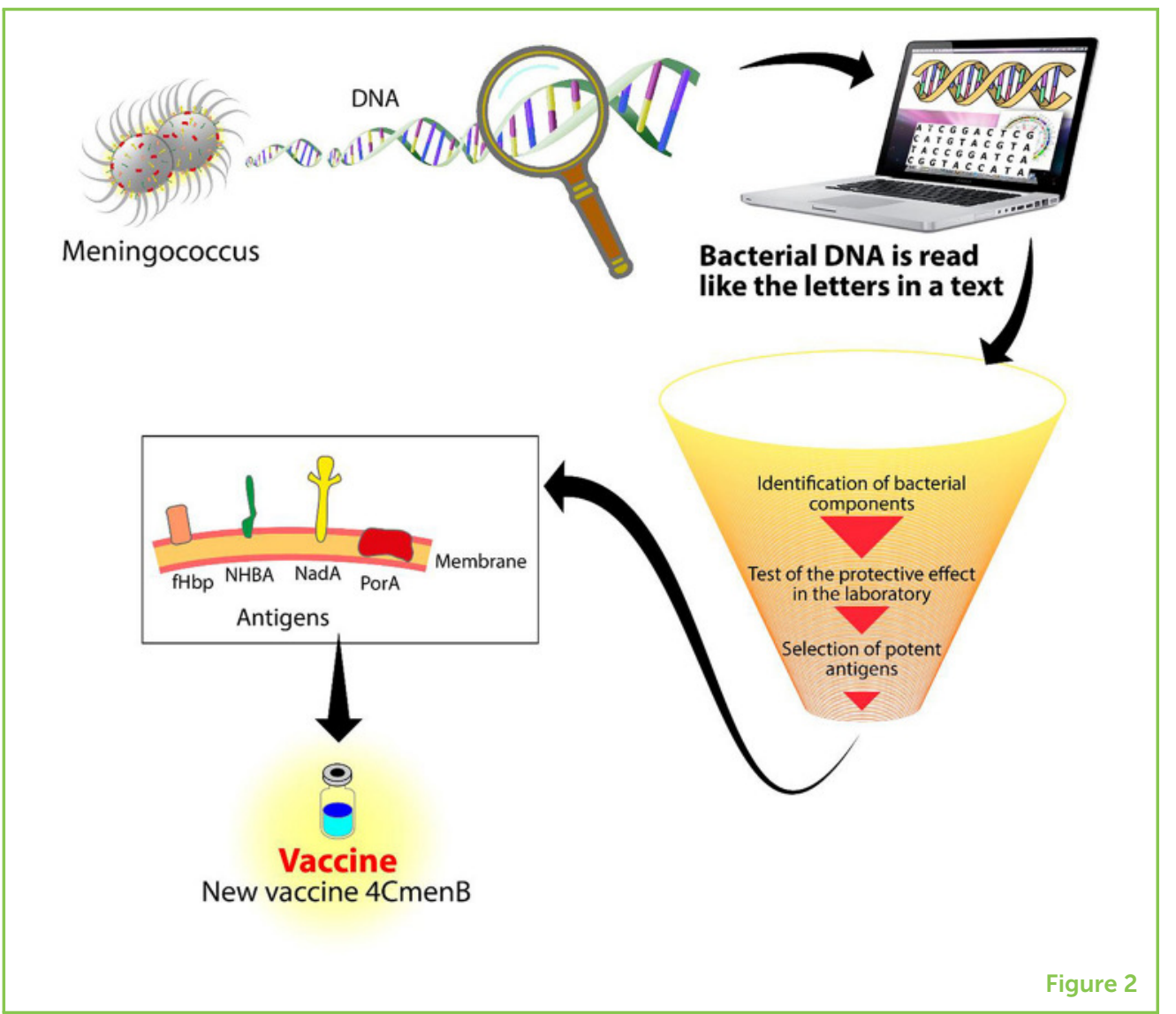

These three antigens play an important role in the ability of meningococcus $B$ to cause disease (Figure 3A). NadA is a sticky antigen that works as an anchor, allowing the bacteria to stick to the internal walls of human nostrils. When bacteria cross the nostril cells and enter the bloodstream, they start to multiply and reach all organs. To circulate in the blood without being attacked by antibodies, meningococcus have evolved several mechanisms to fool the body's defenses. Meningococcus uses fHbp and NHBA as glue to coat their surfaces with substances normally produced by the human body, making them "invisible." However, now that we know these tricks, we can instruct the immune system to produce antibodies against NadA, fHbp, and NHBA and we can block the meningococcus disguise mechanism. By combining these three meningococcal components with a fourth component, PorA, the first vaccine against meningococcus $B$, called $4 C$ MenB, was born.

\section{SAVING CHILDREN FROM MENINGOCOCCUS B}

The UK was the first country that decided to protect its children with the novel 4CMenB vaccine, by introducing this vaccine in a national immunization program in 2015 [5]. In the 5 years since, about 5 million children in the UK have been vaccinated with the new vaccine. As shown in Figure 3B, the use of 4 CMenB has prevented one case of 
Figure 3

Vaccine protection against

meningococcus $B$. (A)

After 4CMenB

vaccination, the body produces antibodies

against

meningococcus.

Antibodies block NadA limiting the ability of

meningococcus to invade cells. Other antibodies block fHbp and NHBA, preventing them from sticking to human proteins (like $\mathrm{fH}$ and heparin) and thus stopping the bacterial disguise mechanism. Finally, other antibodies also block PorA and other components. Covered by antibodies, meningococcus $B$ can do no harm and it is rapidly destroyed. (B) After its introduction in the UK in 2015, the use of 4 CMenB greatly reduced the number of cases of

meningococcal disease in young children.

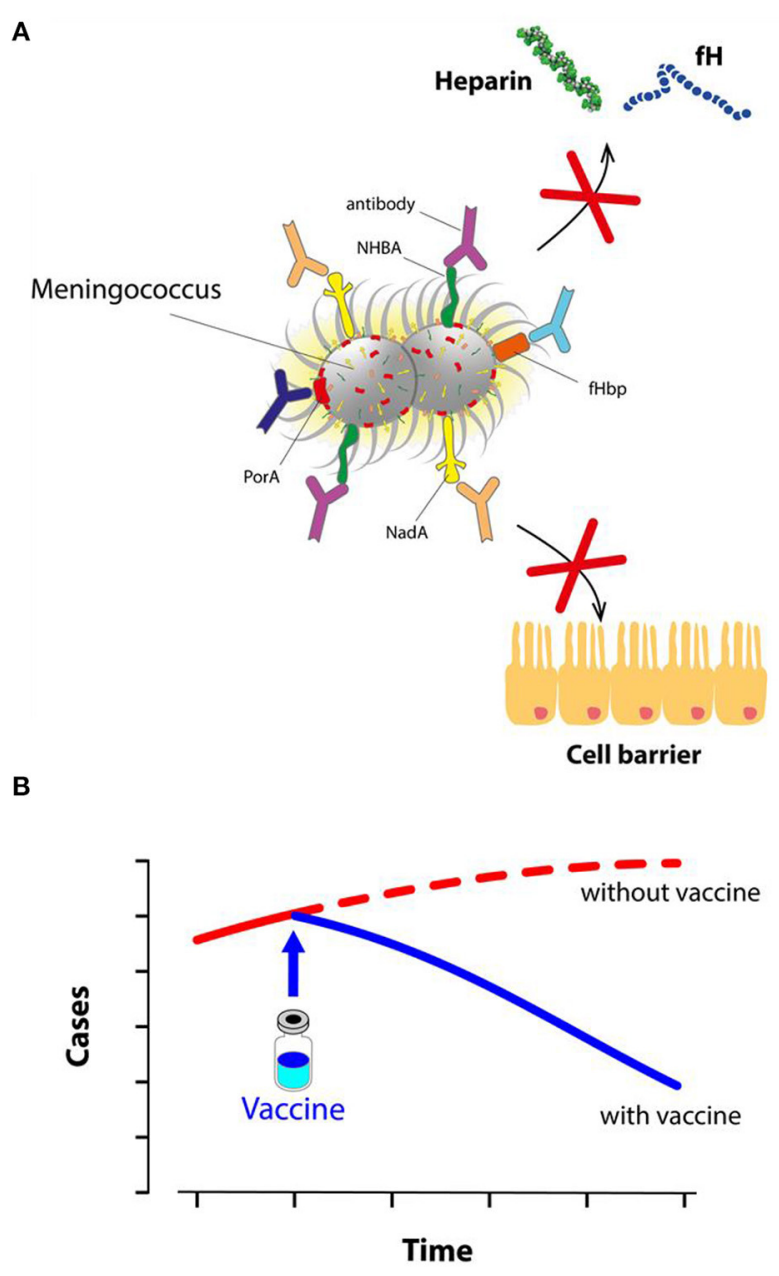

Figure 3

meningococcal disease every 4 days! Today, the 4CMenB vaccine is available in 42 countries all around the world, helping to protect thousands of infants, children, and adolescents from dangerous meningococcal disease.

\section{ACKNOWLEDGMENTS}

We thank Giorgio Corsi for the artwork.

\section{REFERENCES}

1. Micoli, F., Del Bino, L., Alfini, R., Carboni, F., Romano, M. R., and Adamo, R. 2019. Glycoconjugate vaccines: current approaches towards faster vaccine design. Expert Rev. Vaccines 18:881-95. doi: 10.1080/14760584.2019.1657012

2. Rappuoli, R., Pizza, M., Masignani, V., and Vadivelu, K. 2018. Meningococcal B vaccine (4CMenB): the journey from research to real world experience. Expert Rev. Vaccines 17:1111-21. doi: 10.1080/14760584.2018.1547637 
3. Masignani, V., Pizza, M., and Moxon, E. R. 2019. The development of a vaccine against meningococcus B using reverse vaccinology. Front. Immunol. 10:751. doi: 10.3389/fimmu.2019.00751

4. Pizza, M., Scarlato, V., Masignani, V., Giuliani, M. M., Aricò, B., Comanducci, M., et al. 2000. Identification of vaccine candidates against serogroup $B$ meningococcus by whole-genome sequencing. Science 287:1816-20. doi: 10.1126/science.287.5459.1816

5. Ladhani, S. N., Andrews, N., Parikh, S. R., Campbell, H., White, J., Edelstein, M., et al. 2020. Vaccination of infants with meningococcal group $B$ vaccine (4CMenB) in England. N. Engl. J. Med. 382:309-17. doi: 10.1056/NEJMoa1901229

SUBMITTED: 08 May 2020; ACCEPTED: 11 December 2020; PUBLISHED ONLINE: 16 February 2021.

EDITED BY: Michel Goldman, Institute for Interdisciplinary Innovation in healthcare (I3h), Belgium

CITATION: Pecetta S, Masignani V, Pizza M and Rappuoli R (2021) Meningococcal Vaccines: A Technological Revolution. Front. Young Minds 8:560305. doi: 10.3389/ frym.2020.560305

CONFLICT OF INTEREST: SP, VM, MP, and RR are full-time employees of the GSK group of companies. This work was sponsored by GlaxoSmithKline Biologicals SA, a company that has a direct financial interest in producing and marketing vaccines.

COPYRIGHT @ 2021 Pecetta, Masignani, Pizza and Rappuoli. This is an open-access article distributed under the terms of the Creative Commons Attribution License (CC BY). The use, distribution or reproduction in other forums is permitted, provided the original author(s) and the copyright owner(s) are credited and that the original publication in this journal is cited, in accordance with accepted academic practice. No use, distribution or reproduction is permitted which does not comply with these terms.

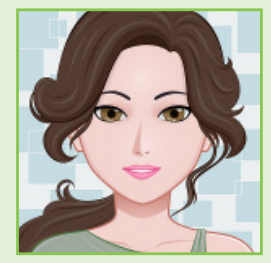

\section{YOUNG REVIEWERS}

\section{AMELIE, AGE: 12}

I have been participating in Frontiers for Young Minds for the past 2 years. Reviewing papers is one of my passions as well as reading, painting, drawing, and writing. Through reading these scientific papers, I have learnt a lot about health and disease. I love to travel and my favorite animal is the pangolin.

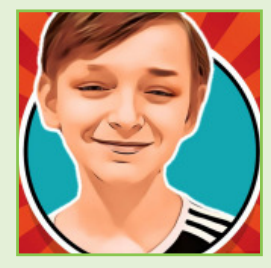

\section{ELLIOT, AGE: 10}

My name is Elliot, and I am 10 years old. I live in a small town in Wisconsin out in the woods. I love almost all science, especially engineering and robotics/coding. I also love playing soccer, playing cello, and almost anything outside. I love to read, particularly the mythologies of many different cultures. I am currently reading the My Dark Materials series. 

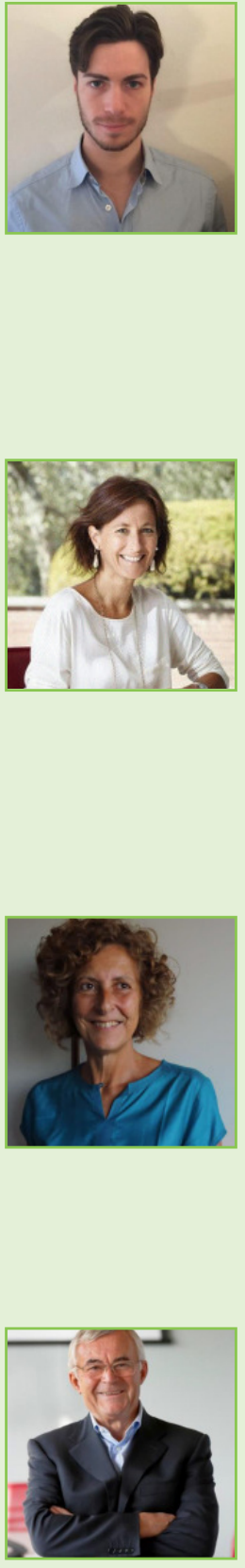

\section{AUTHORS}

\section{SIMONE PECETTA}

Simone Pecetta is a Senior Scientist in GSK Vaccines, with a long-term scientific interest in understanding the immunological mechanisms of vaccination. He has previously worked as post-doctoral scientist at the Francis Crick Institute in London (UK) and at the Ragon Institute of MGH, MIT and Harvard in Boston (USA), studying the biology of $\mathrm{B}$ cells, the antibodies they produce, and their role in the protection from HIV infection. His Ph.D. research, focused on the study of the effect of multiple vaccinations, was conducted at Novartis Vaccines R\&D in collaboration with the University of Rome "Sapienza."

\section{VEGA MASIGNANI}

Vega Masignani holds a Ph.D. in Biotechnology and is currently Vaccine Development Leader at GSK Vaccines in Siena. She was first involved in the computational analysis of the Neisseria meningitides type B genome sequence and in the computer-based identification of novel candidates for the development of $4 C M e n B$, the type $B$ meningococcal vaccine, and contributed to the characterization of the main protein components of $4 C M e n B$. During the past few years, she has also been involved in the research on the identification of novel antigen candidates for Streptococcus pneumoniae and Pseudomonas aeruginosa vaccines.

\section{MARIAGRAZIA PIZZA}

Mariagrazia Pizza is currently Senior Scientific Director for Bacterial Vaccines at GSK Vaccines, in Siena. She contributed to the discovery of a pertussis vaccine based on a genetically detoxified toxin, and to the discovery of a new vaccine against meningococcus B, licensed in many countries worldwide. She has received several awards and is Honorary Visiting Professor at the University of Leicester. She has over 200 publications in international peer-reviewed journals and is co-inventor of many patents.

\section{RINO RAPPUOLI}

Rino Rappuoli is head of the vAMRes laboratory at TLS in Siena and Chief Scientist and Head External R\&D at GSK Vaccines, Siena, Italy. He has received several awards including the Paul Ehrlich and Ludwig Darmstaedter Prize, the Gold Medal by the Italian President, the Albert B. Sabin Gold Medal, the Canada Gairdner International Award, and the European Inventor Award for Lifetime Achievement. He developed the pertussis and meningococcus B vaccines, among others, and was nominated third most influential person worldwide in the field of vaccines. Dr. Rappuoli is among the world's scientific leaders dedicated to the sustainability of global health. *rino.r.rappuoli@gsk.com 